MAKÜ FEBED

ISSN Online: 1309-2243

http://dergipark.ulakbim.gov.tr/makufebed

Mehmet Akif Ersoy Üniversitesi Fen Bilimleri Enstitüsü Dergisi 8(2): 114-122 (2017)

The Journal of Graduate School of Natural and Applied Sciences of Mehmet Akif Ersoy University 8(2): 114-122 (2017)

Araştırma Makalesi / Research Paper

\title{
Burdur Kenti Toplu Konut ve Site Alanlarının Peyzaj Tasarım Yeterliliğinin İncelenmesi
}

\author{
Cengiz YÜCEDAĞ ${ }^{1}$, Latif Gürkan KAYA ${ }^{1 *}$, Altunay ULU² \\ ${ }^{1}$ Mehmet Akif Ersoy Üniversitesi, Mühendislik Mimarlık Fakültesi, Burdur \\ ${ }^{2}$ Mehmet Akif Ersoy Üniversitesi, Fen Bilimleri Enstitüsü, Burdur \\ Geliş Tarihi (Received): 02.04.2017, Kabul Tarihi (Accepted): 12.05.2017 \\ $\square$ Sorumlu Yazar (Corresponding author)*: Igkaya@gmail.com \\ (C) +902482132700 䓝 +902482132704
}

ÖZ

Çalışmanın amacı, Burdur kenti sitelerinin açık ve yeşil alanlarını incelemek ve peyzaj tasarım ölçütlerine göre değerlendirmelerde bulunmaktır. Bu çerçevede, materyal olarak seçilen Toplu Konut İdaresi'nce (TOKI) yapılan konutlar dahil 73 sitede ilk olarak ön etüt yapılmış, sonra veri toplanmış ve son olarak da toplanan bu veriler değerlendirilmiştir. Buna göre, çalışılan sitelerin çoğunluğu güvenlik, otopark, çocuk oyun alanı ve spor alanı bakımından yetersiz bulunmuştur. Oturma-dinlenme alanı, bitkisel tasarım ve peyzaj donatı elemanları bakımından ise sitelerin genel olarak yeterli olduğu tespit edilmiştir. Kullanıcıların toplu konut ve siteleri seçmelerinde, oturma-dinlenme alanları, çocuk oyun alanları, spor alanları, güvenlik, otopark ve bitkisel tasarım ölçütlerinin önemli hususlar olması sebebiyle, yeni inşa edilecek sitelerde bu ölçütlerin ilgili kişi ve kurumlarca göz önüne alınması son derece önemlidir.

Anahtar Kelimeler: Bahçe, konut, peyzaj, site, tasarım, Burdur

\section{Investigation of Landscape Design Efficiency in the Housing Development and the Apartment Complexes of Burdur City, Turkey}

\begin{abstract}
The aim of this study is to examine the open and green lands of Burdur city apartment complexes and evaluate them according to the landscape design criteria. In this framework, 73 apartment complexes including housing made by the Housing Development Administration (TOKI) selected as the material were first preliminarily studied, then the data were collected and finally the collected data were evaluated. Accordingly, the majority of the studied the apartment complexes were found to be inadequate in terms of security, parking, children's playground and sports area. In terms of seating-rest area, plant design and landscaping elements, the sites were generally found to be sufficient. It is very important to be taken these criteria into consideration by relevant people and organizations in the newly constructed the apartment complexes because seating-rest areas, playground, sport lands, security, parking lots and planting design criteria in the selection of mass housing and the apartment complexes are the important points for users.
\end{abstract}

Keywords: Garden, housing, landscape, apartment complexes, design, Burdur 


\section{Giriş}

Gelişmekte olan ülkelerde kentleşme, rahatlama unsurlarını içermeyen ortamları oluşturarak dramatik etkilere neden olmaktadır (Kuchelmeister ve Braatz, 1993). Hızlı bir kentsel gelişme dönemine girildiğinde, kentsel alanlarda açık ve yeşil alanların kaybedilmesi çeşitli olumsuz etkilere neden olmaktadır. Bunlar; bilimsel, endüstriyel, ve teknolojik alanlarda çok sayıda plansız kentleşmeden kaynaklı olumsuzluklar ile zayıf fiziksel ve psikolojik olanlar dahil sağlık ve sosyo-kültürel sorunlardır. Yoğun nüfuslu kentsel alanlar, mevcut tek konutlu ve insanların zorla yaşamak zorunda kaldıkları alanlardır (Cetin, 2015a; Cetin, 2015b; Cetin, 2016a).

1950 yılından bu yana Türkiye'deki kent nüfusu artmaktadır. Artan nüfus ve bozulan çevre koşullarına uyum sağlamak amacıyla çağdaş peyzaj tasarımı kapsamında sürdürülebilirlik ve çevresel koruma politikaları gibi yeni kavramlar gündeme gelmektedir. Bahçeden kente, kentten doğa restorasyonuna kadar sürdürülebilirlik ilkelerinin dikkate alınarak konut ve yakın çevresinin tasarlanması son derece önemlidir (Yaşar ve Düzgüneş, 2013). Günümüzde kentleri daha sağlıklı yaşanılabilir alanlar yapabilmek amacıyla ekolojik, sosyal ve ekonomik açıdan birçok çalışma yapılmaktadır (Kurdoğlu ve ark., 2011).

Bugün, ülke nüfusunun \%77'si kentlerde yaşamaktadır (Atmış ve ark. 2007). Bunların sonucu olarak, konut gereksinimi büyük ölçüde artarken mevcut konut üretimi bu intiyaca cevap verecek ölçüde artmamıştır. Bu konut açığını kısa sürede kapatmak için çok sayıda konut birimini içeren, yaşayan nüfus için gerekli teknik ve sosyal donatı alanları ile birlikte planlanmış bir çevre oluşturan ve bir arada olmasından doğan toplumsal, ekonomik, çevresel ve teknolojik yararlar sağlayabilen yerleşimler olan toplu konutlar ortaya çıkmıştır (Özyavuz ve Dönmez, 2016).

Tarihsel olarak konut; iletişim, etkileşim, mekân, zaman ve anlamın örgütlü bir modelidir. Konut, etnik grupların özelliklerini, hayat stillerini, davranışsal kodlarını, ekolojik seçimlerini, görüntüleri ve zaman mekan sınıflamalarını yansıtır. Diğer taraftan, yine özellikleri nedeniyle konutlar, korunmuş alana sahip, özel kimlik taşıyan mekânlar olarak da ifade edilebilir (Gür, 2000). Yerleşik yaşam kültürünün bir ürünü olarak konut, değişik iklim koşulları ve farklı kültürler sonucunda farklı bölgelerde, farklı yapı malzemesi ve formlarla günümüze kadar gelmiştir (Koçhan ve ark., 2011).

Konutlar, barınma ihtiyacını karşılaması yanında bireylerin farklı sosyo-kültürel yapılarının çevre ile uyumlu olmasını sağlayan bir ara malzeme durumundadır. Bu yönden bakıldığında konutlar, sadece insan gereksinmelerinin karşılandığı fiziksel bir nesne değil, aynı zamanda o mekânda yaşayan insanların kimliğinin yer aldığı sosyal ve kültürel bir birim olarak da görülebilir (Dönmez ve ark., 2015). Bu bakımdan en kısa şekliyle, bireylerin barınma ve sosyal intiyaçlarını karşılamak amacıyla yararlandıkları mekânlar konut olarak tanımlanabilir. Konutlar birçok ölçüte göre farklı şekillerde sınıflandırılabilir (Özyavuz ve Dönmez, 2016). Örneğin, Aydemir ve ark. (2004) konutu, kat sayısına (az katlı, çok katlı ve yüksek bloklar), mülkiyet durumuna (tek sahipli, birden fazla sahipli ve lojmanlar) ve formuna (eklenemeyen ve yüksek bloklar, eklenebilen bloklar, bir katta bir veya daha fazla daireyi barındıran bloklar) göre sınıflandırmıştır.

Konutta fiziksel kullanıcı gereksinimleri mekânsal, ısısal, işitsel, görsel, sağlık ve güvenlik gereksinimleri olmak üzere altı grupta sınıflandırılabilir (Erata, 1998; Fırat, 2001). Bunlar, susuzluk, açlık gibi insanın yaşamını sürdürmesi için gerekli olan gereksinimlerdir (Özyavuz ve Dönmez, 2016). Konutta psiko-sosyal kullanıcı gereksinimleri ise, işitsel ve görsel gizlilik, toplumsal çevrenin insan davranışlarına ilişkin özellikleri, insanın içinde yer aldığı mekâna ilişkin doku, renk, form gibi estetik koşullardır (Erata, 1998).

Konut değerini artıran koşullar; çevrenin tanınır olması, konut ve dış mekân arasındaki doğal ilişki, aktif kullanılan açık alan, özel çevre, aktif şehirsel çevre, sakin doğal çevre, manzara, konut çevresinin düzenli olması, donatıların tam olması ve kirli havadan arındırılmış çevredir. Konut değerini azaltan koşullar ise, merdiven çıkmak, zeminle görsel ilişki olmaması, zeminle duygusal ilişki kurulamaması, anonim komşuluk, bahçe ve konut bakımsızlığı, konut-yeşil alan kopukluğu, ses geçirgenliği, sevimsiz çevre, hareket olanağı vermeyen çevre ve gürültü ve hava kirliliği şeklinde sayılmaktadır (Giritlioğlu, 1991).

Kent, boyutları işlevsel ve estetik niteliklerine bağlı olarak yeşil alanların dağılımı yoluyla sağlıklı bir ortam sağlayabilmelidir. Kentsel yeşil alanlar, kentle ilgili bütüncül bir yaklaşım sağlar. Kentsel yaşam koşulları insanlık arasındaki bozulan ilişkileri dengelemek, planlamak ve doğayı iyileştirmede önemli rol oynar. Bazı şehirlerde, aktif ve pasif yeşil alanların dağılımı, kamusal özelliklerine bağlıdır. Dağınık ve planlanmamış yeşil alanlar, politikası olmayan gelişmekte olan şehirlerde daha yaygındır (Cetin, 2015c; Cetin, 2016b; Cetin ve ark., 2016).

Günümüzde insanların yeşile olan özlemlerini gidermek, doğayla olan ilişkilerini artırmak, aynı zamanda estetik değer kazandırmak için konut bahçeleri öne çıkmaktadır. Türkiye'de çok az kent dışında, konut bahçelerinin planlanması ve tasarımı ile ilgili standartlara uyulmamakta ve ne yazık ki bu konularda yasal yaptırımlar ve 
denetimler bulunmamaktadır. Çoğu zaman konutlara kullanıcıların yerleşmesinden çok sonra genellikle işlevsel olmayan göstermelik konut bahçeleri oluşturulmaktadır. Ayrıca, kentsel açık yeşil alanlardan biri olan konut ve toplu konut bahçelerinde hem estetik hem de bitkisel materyaller bakımından önemli eksiklikler mevcuttur. Aslında, insanların konutlarında rahat, güvenli, mutlu şekilde yaşayabilmeleri için, konutun olduğu kadar konut bahçelerinin de iyi planlanması ve tasarlanması gerekmektedir. Bu çalışmanın amacı, Burdur kenti sitelerinin açık ve yeşil alanlarını incelemek ve peyzaj tasarım ölçütlerine göre değerlendirmelerde bulunmaktır.

\section{MATERYAL VE YÖNTEM}

Bu çalışmada materyal olarak, Burdur merkez ilçesinde yer alan siteler ele alınmıştır. Bu çerçevede TOKİ tarafından yapılan konutlarda dahil 73 site seçilmiştir (Şekil 1). Sitelerin seçiminde, basit ve anlaşılır olması bakımından Aydemir ve ark. (2004) tarafından yapılan konut Sınıflaması temel alınmıştır. Bu anlamda, sitelerin yeşil alana ve en az iki konuta sahip olmalarına dikkat edilmiştir. Ayrıca, site sakinleri ve görevliler ile gerçekleştirilen mülakatlar da çalışmanın materyalini oluşturmuştur.

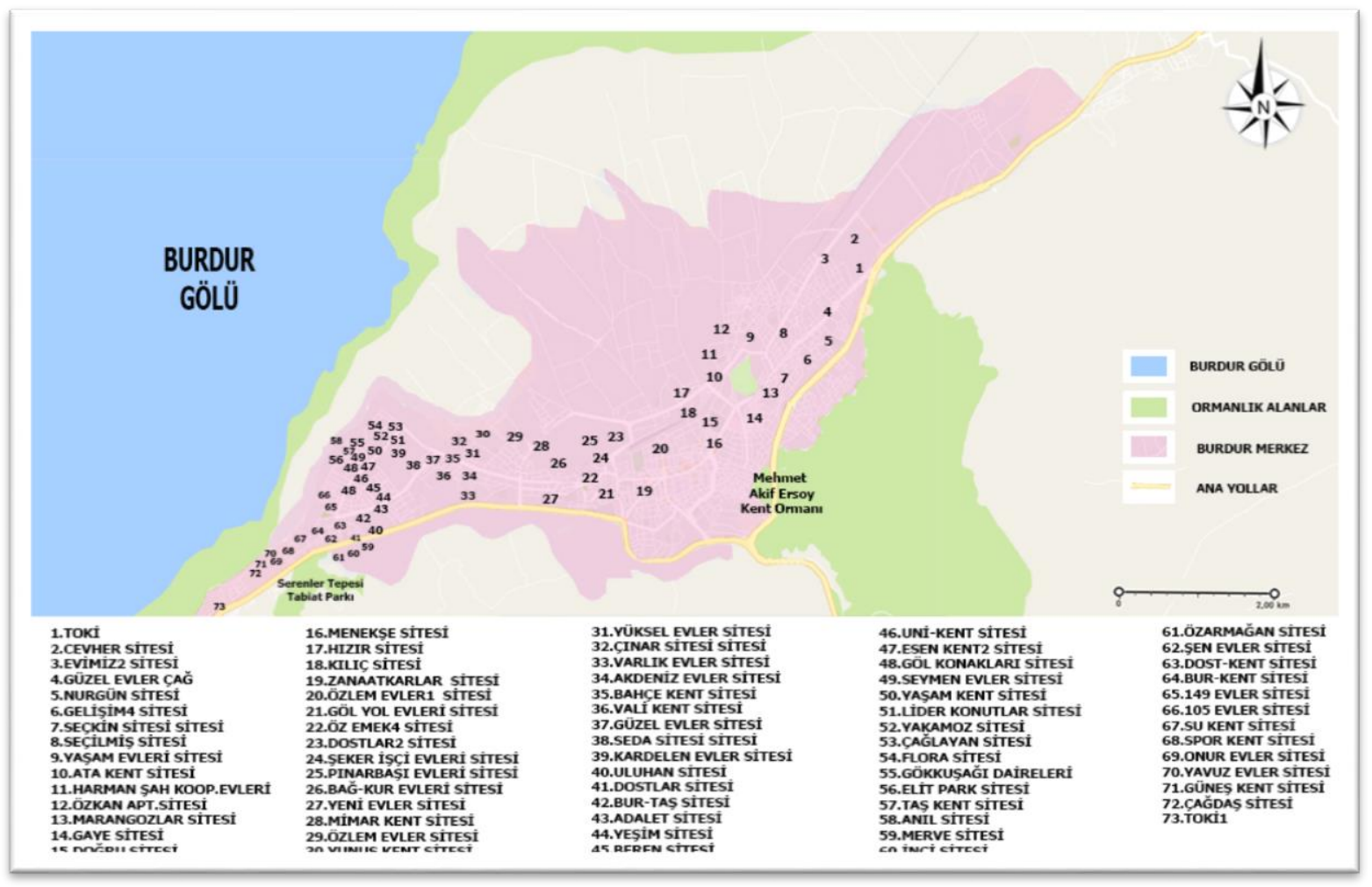

Şekil 1. Çalışılan Sitelerin Konumları

$37^{\circ} 43^{\prime}$ kuzey enlemi ile $30^{\circ} 17^{\prime}$ doğu boylamı arasında yer alan Burdur ilinin, batısında Denizli, güney batısında Muğla, güneyinde Antalya, kuzeyinde Afyonkarahisar ve kuzey doğusunda Isparta illeri bulmaktadır. İ,,967m rakıma sahiptir ve $2659 \mathrm{~m}^{2}$ yüzölçümü ile Türkiye toplam yüzölçümünün \%0,9'unu teşkil eder. Burdur'un ikliminde Akdeniz iklimi ile Karasal iklim arasında geçiş özeliğinin egemen olduğu görülür (DMi, 2009). Buna göre, yaz mevsimi sıcak ve kurak, kış mevsimi ise oldukça soğuk geçmektedir. Yıllık ortalama sıcaklık $13 \mathrm{C}^{\circ}$ ve yıllık ortalama yağış miktarı 405 mm'dir (DMi, 2009; Yiğitbaşıoğlu ve Uğur, 2010; Kaya ve ark., 2015).

Yeni kentleşen Türkiye illerinden birisi konumunda olan Burdur'un merkez toplam nüfusu 104.875'dir (TÜİK,
2016). Özellikle 2006 yılında Mehmet Akif Ersoy Üniversitesi'nin kuruluşuyla, Burdur ilinin sosyal, ekonomik ve kültürel yapısı hızlıca değişmektedir.

Burdur, genellikle dağınık halde değişik rekreasyon alanlarına (piknik alanları, mahalle parkları, çocuk oyun alanları, spor alanları vb.) sahiptir. Bu alanlarda mevcut vejetasyon örtüsü ve fiziki altyapı estetik ve işlevsel özellikler açısından sakinlerin ve ziyaretçilerin gereksinimlerini karşılamak için yetersizdir. Kent Burdur Gölü, Salda Gölü Tabiat Parkı, Serenler Tepesi Tabiat Parkı, platolar, şelaleler, plajlar ve arkeolojik vb. yapılar zengin doğal ve kültürel değerlere sahiptir. 
Burdur ormanlarında Kızılçam (Pinus brutia Ten.), Anadolu karaçamı [Pinus nigra Arnold subsp. pallasiana (Lamb.)], Toros göknarı (Abies cilicica Carr.), Toros sediri (Cedruslibani A. Rich, ardıç türleri (Juniperus sp.), meşe türleri (Quercus sp.), Anadolu sığlası (Liquidambar orientalis Mill.) ve Akasya türleri (Acacia sp.) egemen orman ağacı türleridir. Ayrıca, kızılcık (Cornus mas L.), alıç türleri (Crateagus sp.), katran ardıcı (Juniperus oxycedrus L.), gül (Rosacanina L.), adi mersin (Myrtus communis Linn.), sandal (Arbutus andrachne L.), zeytin (Olea europaea L.), sumak (Rhus coriaria L.), akçakesme (Phillyrea latifolia L.), böğürtlen (Rubus fruticosus L.), teşbih çalısı (Styrax officinalis L.) ve kermes meşesi (Quercus coccifera L.) gibi ağaççık ve çalılar da ilin ormanlarında bulunur (Yücedağ ve ark., 2016).

Çalışmada ilk olarak ön etüt çalışması yapılmıştır. Yani, Burdur merkez ilçede yer alan tüm mahallelerdeki siteler gezilerek ve buralarda ön incelemeler yapılarak, çalışmaya uygun potansiyele sahip alanlar belirlenmiştir. İkinci olarak, veriler toplanmıştır. Belirlenen siteler ile ilgili verilerin düzenli bir şekilde toplanması ve değerlendirilmesi amacıyla "Değerlendirme Formları" hazırlanmıştır. Hazırlanan bu formlarda toplu konut ve sitelerde olması gereken ölçütler göz önüne alınmıştır (Eti, 1994;
Demir, 1998; Erata, 1998; Sayan, 2000; Aslan, 2007). Bu amaçla kullanılan ölçütler; blok sayısı, daire sayısı, güvenlik (site giriş-çıkış), otopark (sayı ve yeterlilik), oturma-dinlenme alanları ve birimleri, çocuk oyun alanı, spor alanları, bitkisel tasarım (fonksiyonel ve işlevsel) ve peyzaj donatı elemanlarıdır. Son olarak ise, veriler değerlendirilmiştir. Siteler ile ilgili doldurulan değerlendirme formları yorumlanmış, görsel ögelere de dayanarak siteler hem yapısal hem de bitkisel açıdan değerlendirilmiştir.

\section{BULGULAR VE TARTIŞMA}

Çalışmada incelenen sitelere ilişkin bulgular Tablo 1 ve Şekil 2'de verilmiştir. Buna göre, sitelere giriş-çıkış kontrolünü sağlamak için, sitelerin \%36'sında güvenlik birimi bulunmaktadır (Şekil 3). Dönmez ve ark. (2015) Safranbolu ilçesi siteleri için güvenlik ölçütünü \%12 mevcut bulurken, Özyavuz ve Dönmez (2016) Tekirdağ ili sitelerinde bu ölçütü \%36 olarak rapor etmişlerdir. Çalışmadaki sitelerin büyük çoğunluğunda siteye ve otoparklara giriş çıkışlarda güvenlik noktasının olmadığı ortaya çıkmıştır. Otopark güvenliğinin otomatik geçiş sistemleri ile sağlandığı, yaya girişlerinde ise çoğunlukla herhangi bir güvenlik sisteminin olmadığı görülmüştür.

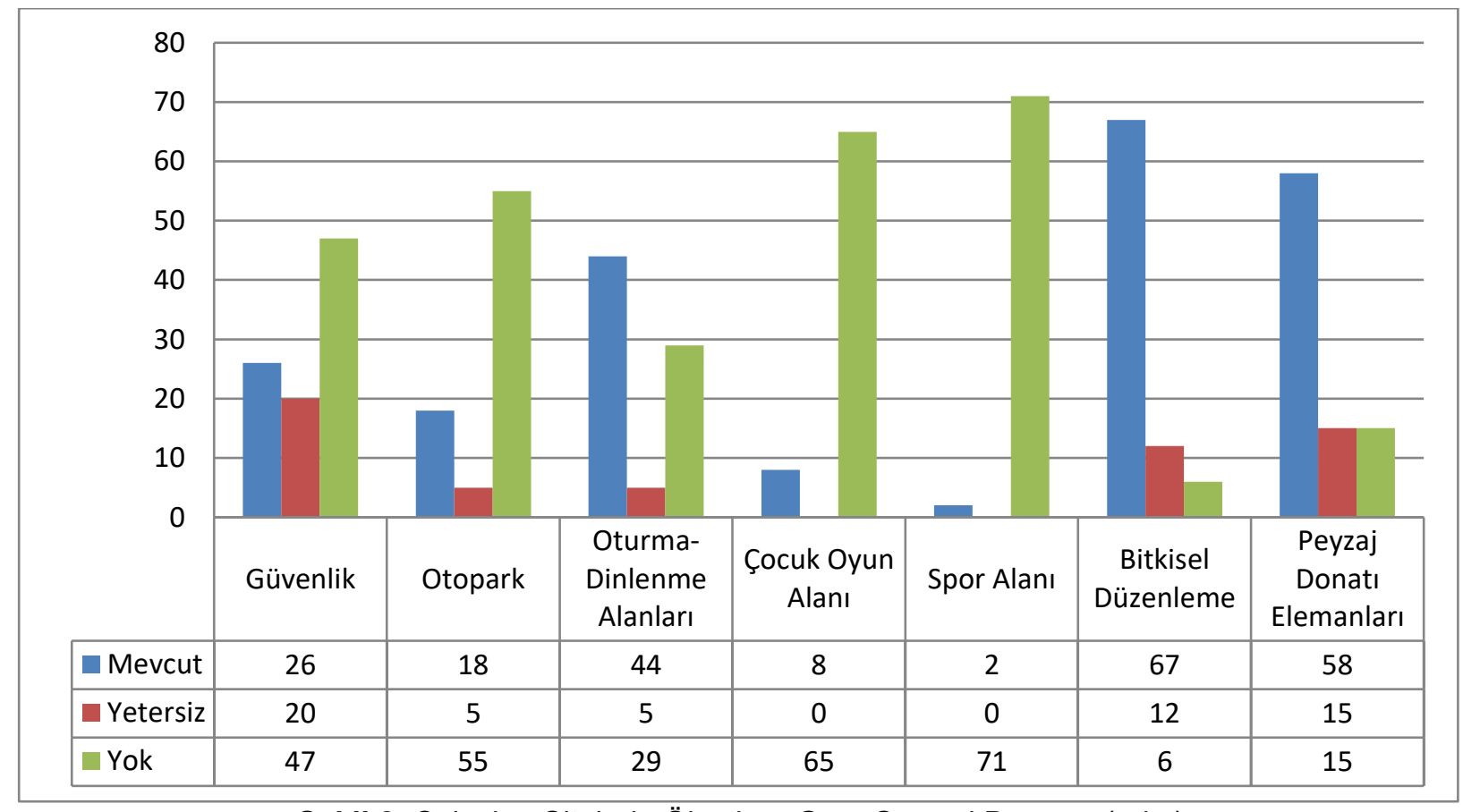

Şekil 2. Çalışılan Sitelerin Ölçütlere Göre Sayısal Durumu (adet) 
Tablo 1. Çalışılan Sitelere İlişkin Bulgular

\begin{tabular}{|c|c|c|c|c|c|c|c|c|}
\hline No & Siteler & Güvenlik & Otopark & $\begin{array}{l}\text { Oturma-Din- } \\
\text { lenme Alan- } \\
\text { ları }\end{array}$ & $\begin{array}{l}\text { Çocuk } \\
\text { Oyun } \\
\text { Alanı }\end{array}$ & $\begin{array}{l}\text { Spor } \\
\text { Alanı }\end{array}$ & $\begin{array}{l}\text { Bitkisel Ta- } \\
\text { sarım }\end{array}$ & $\begin{array}{c}\text { Peyzaj- } \\
\text { Donatı Ele- } \\
\text { manları }\end{array}$ \\
\hline 1 & TOKi & & $\mathbf{x}$ & $\mathrm{X}$ & $x$ & $\mathbf{x}$ & $\mathbf{x}$ & $\mathrm{X}$ \\
\hline 2 & Cevher Sitesi & & & $x$ & & & $\mathrm{x}$ & $\mathrm{x}$ \\
\hline 3 & Evimiz Sitesi & & & & & & X (Yetersiz) & X (Yetersiz) \\
\hline 4 & $\begin{array}{l}\text { Güzel Evler Çağ Si- } \\
\text { tesi }\end{array}$ & & & $x$ & & & $x$ & X (Yetersiz) \\
\hline 5 & Nurgün Sitesi & & $x$ & $\mathrm{x}$ & & & $x$ & \\
\hline 6 & Gelişim Sitesi & & & & & & $\mathrm{X}$ & $\mathrm{X}$ \\
\hline 7 & Seçkin Sitesi & & & & & & & \\
\hline 8 & Seçilmiş Sitesi & & & $\mathrm{x}$ & & & $x$ & $\mathrm{x}$ \\
\hline 9 & Yaşam Evleri Sitesi & & & $\mathrm{x}$ & & & $\mathrm{x}$ & $\mathrm{x}$ \\
\hline 10 & Ata Kent Sitesi & & & & & & & \\
\hline 11 & $\begin{array}{l}\text { Harman Şah Koop. } \\
\text { Evleri }\end{array}$ & & & & & & $\mathrm{x}$ & \\
\hline 12 & Özkan Apt. Sitesi & & X (Yetersiz) & & & & X (Yetersiz) & \\
\hline 13 & Marangozlar Sitesi & & $x$ & $x$ & & & $x$ & $\mathrm{x}$ \\
\hline 14 & Gaye Sitesi & & & & & & $x$ & $x$ \\
\hline 15 & Doğru Sitesi & & & & & & & \\
\hline 16 & Menekşe Sitesi & & & & & & & \\
\hline 17 & Hızır Sitesi & & & & & & $\mathrm{x}$ & X (Yetersiz) \\
\hline 18 & Kılıç Sitesi & & X (Yetersiz) & & & & $x$ & X (Yetersiz) \\
\hline 19 & Zanaatkarlar Sitesi & & & & & & & \\
\hline 20 & Özlem Evler1 Sitesi & & & & & & X (Yetersiz) & \\
\hline 21 & Göl Yol Evler & & & & & & X (Yetersiz) & \\
\hline 22 & Öz Emek4 Sitesi & & & & & & $\mathrm{X}$ & X (Yetersiz) \\
\hline 23 & Dostlar2 Sitesi & & & $\mathrm{x}$ & & & $x$ & $x$ \\
\hline 24 & $\begin{array}{l}\text { Şeker İşçi Evleri Si- } \\
\text { tesi }\end{array}$ & & & X (Yetersiz) & & & X (Yetersiz) & X (Yetersiz) \\
\hline 25 & $\begin{array}{l}\text { Pınarbaşı Evleri Si- } \\
\text { tesi }\end{array}$ & & & & & & X (Yetersiz) & \\
\hline 26 & $\begin{array}{l}\text { Bağ-Kur Evleri Si- } \\
\text { tesi }\end{array}$ & & & & & & X (Yetersiz) & X (Yetersiz) \\
\hline 27 & Yeni Evler Sitesi & & & $\mathrm{X}$ & & & $x$ & $\mathrm{x}$ \\
\hline 28 & Mimar Kent Sitesi & & $\mathrm{x}$ & $x$ & & & $\mathrm{x}$ & $x$ \\
\hline 29 & Özlem Evler Sitesi & & & $x$ & & & $x$ & $x$ \\
\hline 30 & Yunus Kent Sitesi & & & $x$ & & & $x$ & $x$ \\
\hline 31 & Yüksel Evler Sitesi & X (Yetersiz) & & $x$ & & & $x$ & $x$ \\
\hline 32 & Çınar Sitesi & $\mathrm{X}$ (Yetersiz) & & $\mathrm{x}$ & & & $\mathrm{x}$ & $x$ \\
\hline 33 & Varlık Evler Sitesi & $\mathrm{X}$ (Yetersiz) & & $x$ & & & $\mathrm{x}$ & $x$ \\
\hline 34 & Akdeniz Evler Sitesi & $\mathrm{X}$ (Yetersiz) & $\mathrm{x}$ & $\mathrm{x}$ & & & $x$ & $x$ \\
\hline 35 & Bahçe Kent Sitesi & & & & & & X (Yetersiz) & X (Yetersiz) \\
\hline 36 & Vali Kent Sitesi & & & & & & $x$ & $\mathrm{X}$ \\
\hline 37 & Güzel Evler Sitesi & X (Yetersiz) & & $\mathrm{x}$ & & & $x$ & $x$ \\
\hline 38 & Seda Sitesi & X (Yetersiz) & & $x$ & & & $x$ & $x$ \\
\hline 39 & Kardelen Evler Sit. & & & & & & & \\
\hline 40 & Uluhan Sitesi & & & & & & X (Yetersiz) & \\
\hline 41 & Dostlar Sitesi & & & X (Yetersiz) & & & $x$ & X (Yetersiz) \\
\hline 42 & Bur-Taş Sitesi & & & & & & $x$ & X (Yetersiz) \\
\hline 43 & Adalet Sitesi & X (Yetersiz) & & & & & $x$ & $\mathrm{X}$ \\
\hline 44 & Yeşim Sitesi & $\mathrm{X}$ & & $\mathrm{x}$ & & & $\mathrm{x}$ & $x$ \\
\hline 45 & Beren Sitesi & X (Yetersiz) & & $\mathrm{x}$ & & & $\mathrm{x}$ & $x$ \\
\hline 46 & Üni-Kent Sitesi & $x$ & & $x$ & & & $x$ & $x$ \\
\hline 47 & Esenkent Sitesi & & & X (Yetersiz) & & & $X$ (Yetersiz) & $X$ (Yetersiz) \\
\hline 48 & Göl Konakları Sitesi & $x$ & $x$ & $x$ & & & $x$ & $\mathrm{x}$ \\
\hline 49 & Seymen Evler Sitesi & $\mathrm{x}$ & & $x$ & & & $\mathrm{x}$ & $\mathrm{x}$ \\
\hline 50 & Yaşam Kent Sitesi & X (Yetersiz) & & $x$ & & & $\mathrm{x}$ & $\mathrm{x}$ \\
\hline 51 & Lider Konutları Si- & X (Yetersiz) & & $\mathrm{x}$ & & & $x$ & $x$ \\
\hline 52 & Yakamoz Sitesi & $\mathbf{x}$ & $\mathbf{x}$ & $\mathbf{x}$ & $\mathbf{x}$ & $\mathbf{x}$ & $\mathbf{x}$ & $\mathbf{x}$ \\
\hline
\end{tabular}




\begin{tabular}{|c|c|c|c|c|c|c|c|c|}
\hline 53 & Çağlayan Sitesi & X (Yetersiz) & & $\mathrm{x}$ & $\mathrm{x}$ & & $\mathrm{x}$ & $\mathrm{x}$ \\
\hline 54 & Flora Sitesi & X (Yetersiz) & X (Yetersiz) & $\mathrm{x}$ & $\mathrm{x}$ & & $\mathrm{x}$ & $x$ \\
\hline 55 & Gökkuşağı Daireleri & X (Yetersiz) & $x$ & & & & $\mathrm{x}$ & $\mathrm{x}$ \\
\hline 56 & Elit Park Sitesi & $x$ & $\mathrm{x}$ & $\mathrm{x}$ & & & $x$ & $\mathrm{x}$ \\
\hline 57 & Taşkent Sitesi & X (Yetersiz) & & $\mathrm{x}$ & & & $\mathrm{x}$ & $\mathrm{x}$ \\
\hline 58 & Anıl Sitesi & & & $\mathrm{x}$ & & & $\mathrm{X}$ & $\mathrm{x}$ \\
\hline 59 & Merve Sitesi & X (Yetersiz) & & $\mathrm{x}$ & $\mathrm{x}$ & & $x$ & $\mathrm{x}$ \\
\hline 60 & İnci Sitesi & X (Yetersiz) & $\mathrm{x}$ & $\mathrm{x}$ & & & $\mathrm{x}$ & $\mathrm{x}$ \\
\hline 61 & Özarmağan Sitesi & & $x$ & $x$ & & & $x$ & $x$ \\
\hline 62 & Şen Evler Sitesi & X (Yetersiz) & $\mathrm{X}$ & $\mathrm{X}$ & $\mathrm{x}$ & & $\mathrm{X}$ & $x$ \\
\hline 63 & Dost-Kent Sitesi & $\mathrm{X}$ (Yetersiz) & $\mathrm{x}$ & $\mathrm{x}$ & $\mathrm{x}$ & & $x$ & $x$ \\
\hline 64 & Bur-kent sitesi & & & & & & $x$ & X (Yetersiz) \\
\hline 65 & 149 Evler Sitesi & & & & & & $x$ & \\
\hline 66 & 105 Evler Sitesi & & & & & & $\mathrm{X}$ (Yetersiz) & \\
\hline 67 & Su Kent Sitesi & & & & & & $x$ & $X$ (Yetersiz) \\
\hline 68 & Spor Kent Sitesi & X (Yetersiz) & & $\mathrm{x}$ & & & $\mathrm{X}$ & $x$ \\
\hline 69 & Onur Evler Sitesi & X (Yetersiz) & & X (Yetersiz) & & & $\mathrm{x}$ & X \\
\hline 70 & Yavuz Evler Sitesi & & & & & & X (Yetersiz) & $X$ (Yetersiz) \\
\hline 71 & Güneş Kent Sitesi & X (Yetersiz) & & $\mathrm{x}$ & & & $\mathrm{X}$ & $x$ \\
\hline 72 & Çağdaş Sitesi & & X (Yetersiz) & X (Yetersiz) & & & $\mathrm{x}$ & $X$ (Yetersiz) \\
\hline 73 & TOKI 1 & X (Yetersiz) & $\mathrm{X}$ (Yetersiz) & $x$ & $\mathrm{x}$ & & $\mathrm{X}$ & $x$ \\
\hline & Mevcut (\%) & 36 & 25 & 60 & 11 & 3 & 92 & 79 \\
\hline & Mevcut ve Yeterli (\%) & 8 & 16 & 53 & 11 & 3 & 74 & 59 \\
\hline
\end{tabular}

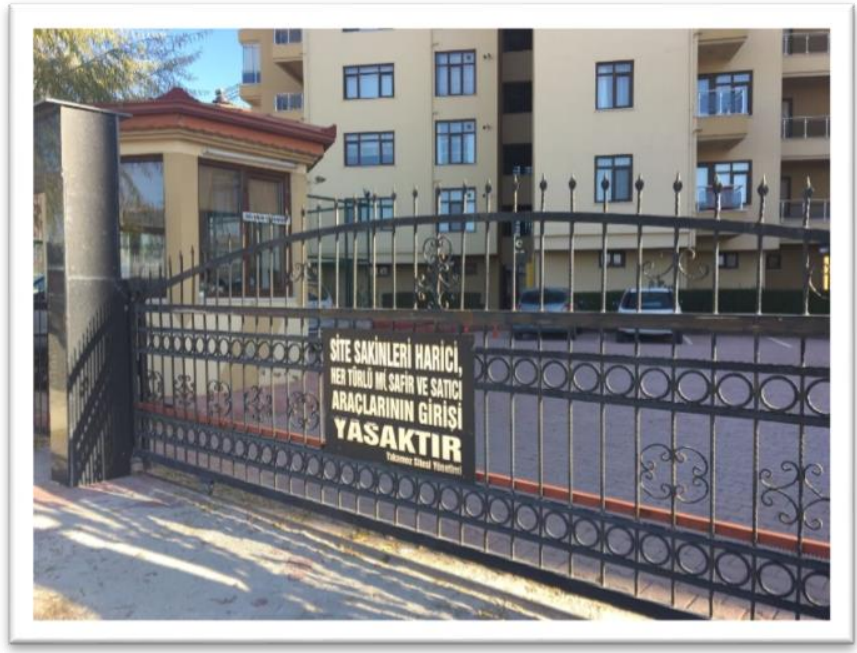

Şekil 3. Site Girişi ve Güvenlik Birimi (Yakamoz Sitesi)

Sitelerin \%25'inde otopark mevcut olup, bunların \%16'sı yeterli durumdadır (Şekil 4). Dönmez ve ark. (2015) Safranbolu ilçesi sitelerinin \%72'sinde, Özyavuz ve Dönmez (2016) Tekirdağ ili sitelerinin \%82'sinde otoparkın mevcut olduğunu bulmuşlardır. Toplu konut uygulamalarında 2 daire için 1 araçlık park yeri öngörülmektedir (Erdoğan, 2009). Sitelerin çoğu mevcut ve yeterli otoparka sahip değildir. Bu nedenle de, bu sitelerde konut sahipleri araçlarını site sınırları dışına yol kenarlarına bırakmaktadırlar. Böyle bir uygulama ise, hem konut sahiplerini tehlikeye sokmakta hem de diğer kent sakinlerini tehdit ve rahatsız etmektedir. Yeterli otoparka sahip olan sitelerde ise araçların park edeceği çizgi ve ayıraçlara yer verilmemesi düzensizliğe ve tehlikelere sebep olabil- mektedir. Bu nedenle, günümüzdeki hususi araç sayısındaki artış dikkate alınarak, yapılacak yeni uygulamalarda daire başına düşen otopark sayısı artırılmalıdır.

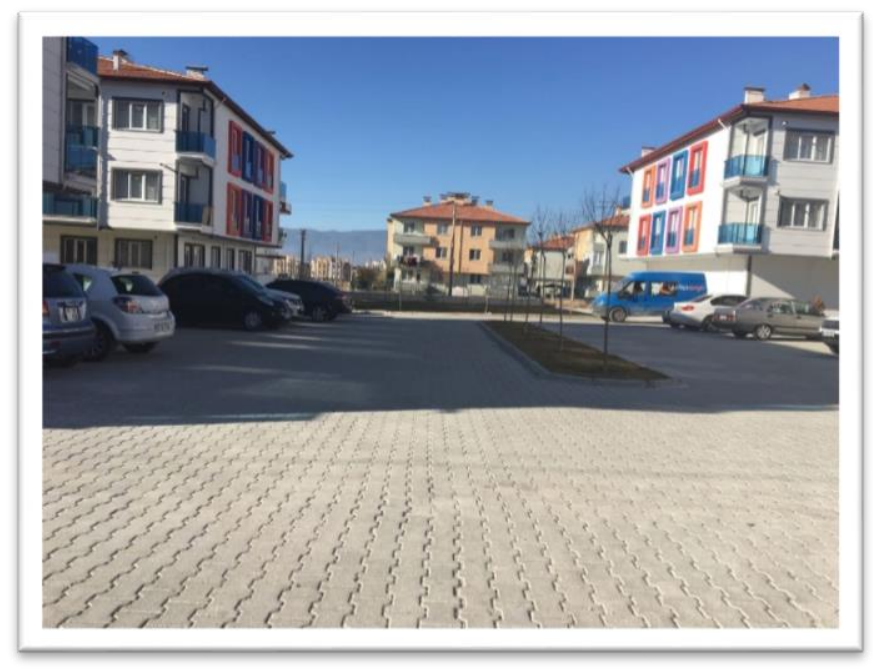

Şekil 4. Site otoparkı (Gökkuşağı Daireleri)

Sitelerin \%60'ında oturma-dinlenme alanı mevcuttur ve sadece \%7'si yetersiz ve/veya bakımsızdır (Şekil 5). Dönmez ve ark. (2015) Safranbolu ilçesi sitelerinin \%43'ünde, Özyavuz ve Dönmez (2016) Tekirdağ ili sitelerinin \%74'ünde oturma-dinlenme alanının mevcut olduğunu tespit etmişlerdir. Ancak, Özyavuz ve Dönmez (2016) mevcut oturma-dinlenme alanının \%41'inin yeteriz olduğunu belirtmişlerdir. Sitelerin yarıdan fazlasının bahçelerinde insanların eğlence-dinlence etkinliklerini yerine getirebilmelerini sağlayacak nitelikte yeterli oturma dinlenme alanlarına sahip olduğu anlaşıımıştır. Sitelerin genelinde yürüyüş yollarına ve site giriş kapısı 
önünü yerleştirilmiş banklar ile kameriye ve pergolalara konulan piknik masalarına rastlanmıştır. Nitekim Özçatalbaş ve Erdoğan (2013) Akdeniz bahçelerinin olmazsa olmazları arasında yer alan pergola ve teraslarla insanların oturma mekanları intiyacına cevap verildiğini ve bunların yanında taşınabilir malzemelerden oluşan taş, ahşap ve mermer oturma birimlerinin de kullanıldığını belirtmişlerdir.

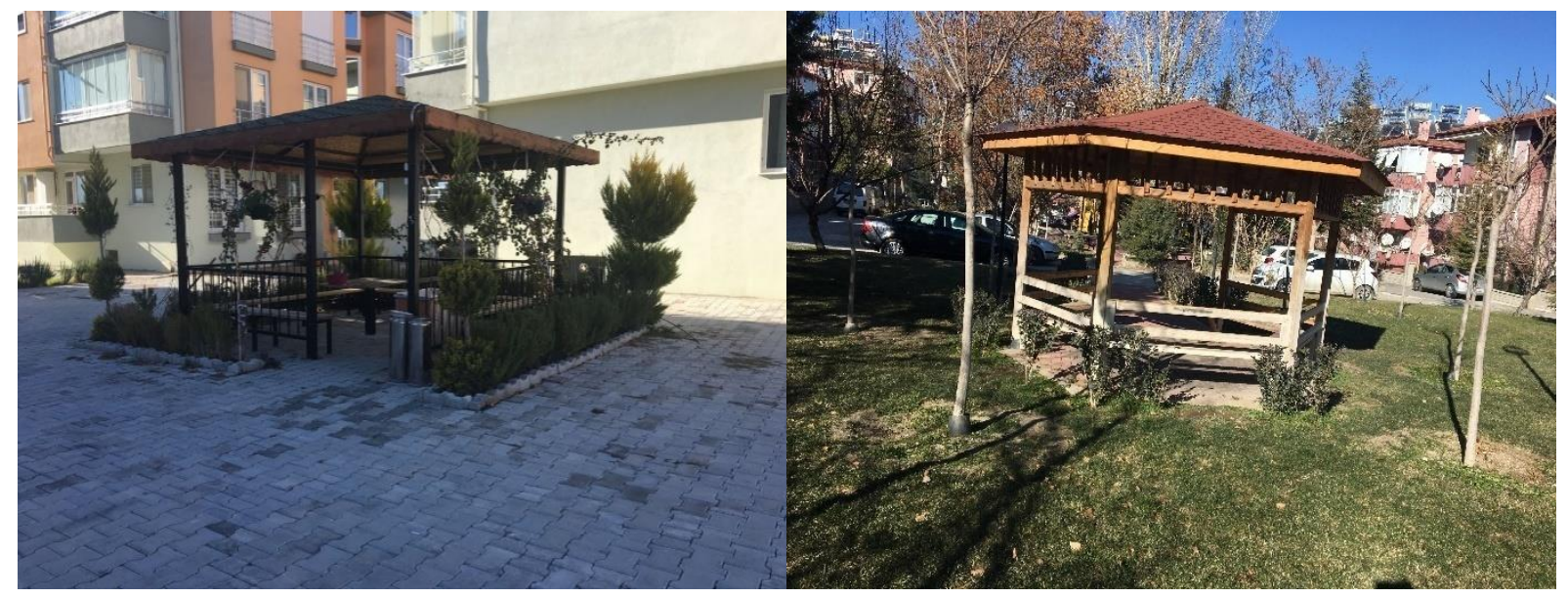

Şekil 5. Site Oturma-Dinlenme Alanları (Flora ve Nurgün Siteleri)

Sitelerin sadece \%11'inde çocuk oyun alanı bulunmuş ve bunların tamamı yeterli niteliktedir. Sitelerin sadece \%3'ünde spor alanı mevcuttur (Şekil 6). Dönmez ve ark. (2015) Safranbolu ilçesi sitelerinin \%22'sinde çocuk oyun alanı ve \%5'inde spor alanı mevcut olduğunu bildirmişlerdir. Özyavuz ve Dönmez (2016) ise Tekirdağ ili sitelerinin \%29'unda çocuk oyun alanı ve \%15'inde spor alanı mevcut olduğunu bulmuşlardır. Çok az sayıda sitede çocuk oyun ve spor alanları mevcuttur. Bu alanların mevcut olması site sakinleri için çok önemli olmasına rağmen, site yapım aşamasında alan büyüklüğünün sınırlayıcılığı veya özellikle site yapımından sonra ortaya çıkacak konut başı maliyetin yüksekliği bu alanların oluşturulmasının gözardı edilmesine neden olabilmektedir. Gerçekte, Erdoğan (2009) tarafından çocukların spor yapma ihtiyacını karşılayacak daha küçük ölçekli spor alanları yapımının ve planlanmasının toplu konutlar için zorunlu bir uygulama ölçütü olduğu ifade edilmiştir.

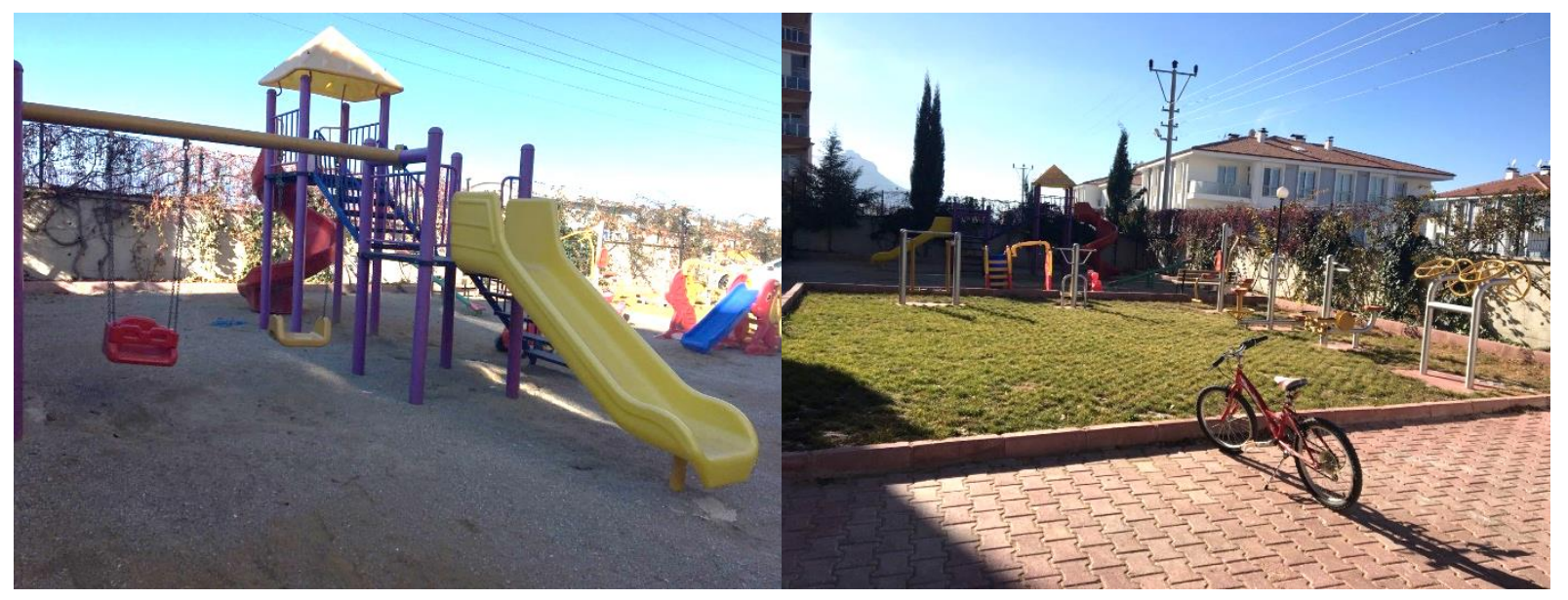

Şekil 6. Site Çocuk Oyun ve Spor Alanları (Yakamoz Sitesi)

Sitelerde yapılan bitkisel tasarımlar (fonksiyonel ve işlevsel) özelliklerine göre değerlendirildiğinde, sitelerin $\% 92$ 'sinde bitkisel tasarım mevcut ve bunun da \%74'ü yeterli düzeydedir. Dönmez ve ark. (2015) Safranbolu ilçesi sitelerinin sadece \%19'unda, Özyavuz ve Dönmez
(2016) Tekirdağ ili sitelerinin \%25'inde yeterli bir bitkisel tasarım olduğunu vurgulamışlardır. Site bahçeleri bitkisel tasarım bakımından yeterli düzeyde görülmüştür. Bitki seçiminde daha çok herdem yeşil bitkilere öncelik verilmiştir. Ancak, genelde bitkilerin estetik ve işlevsel 
gerekleri yerine getirmediği ve özellikle çim alanlarının çok az olduğu da tespit edilen hususlardandır. Sitelerin yapımı yanında bitkilerin rüzgâr kontrolü, gürültü kirliğini azaltılma, gölgeleme gibi işlevlerinin de planlamalarda düşünülmesi ve bu özelliklerinden faydalanılacak şe- kilde bitkisel tasarım yapılması gerekir. Ayrıca, site bahçelerinde genellikle otopark ve yol amaçlı yapılan sert zeminin toprak zemine kıyasla daha fazla alan kapladığı görülmüştür.

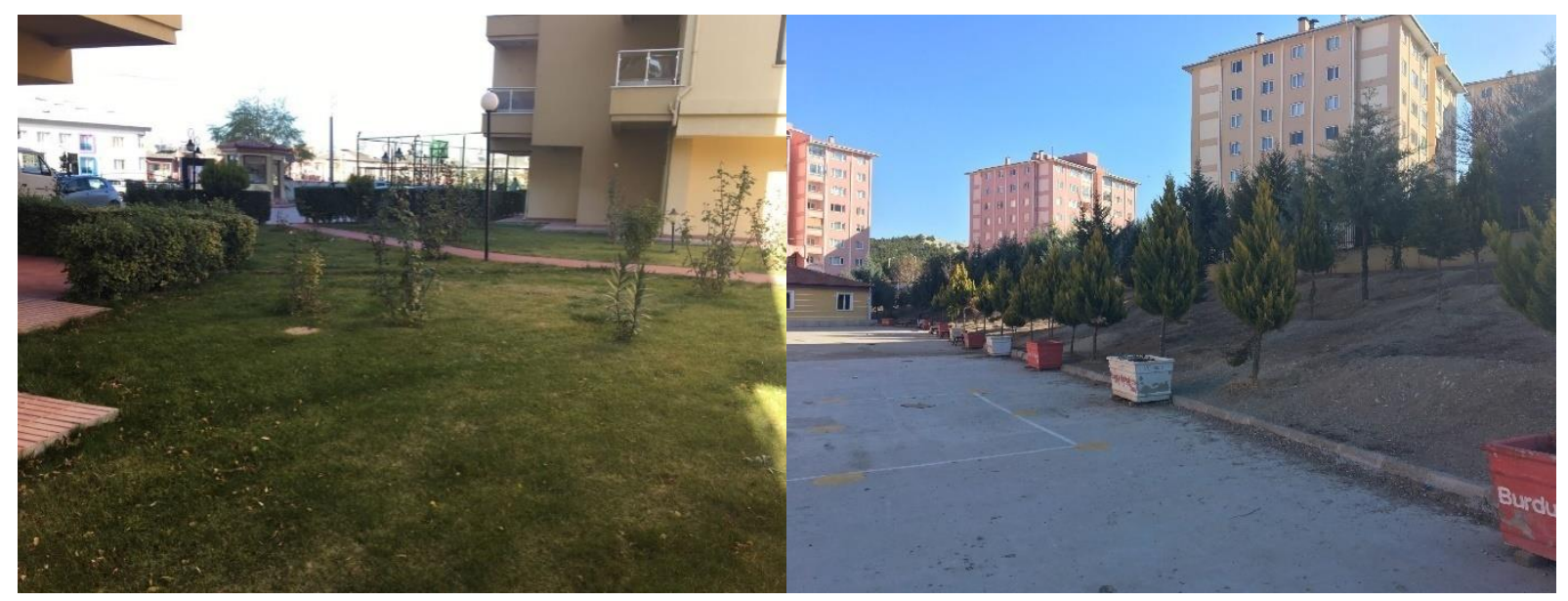

Şekil 7. Site Bitkisel Tasarımları (Yakamoz Sitesi ve TOKI)

Sitelerin \%79'unda peyzaj donatı elemanları kullanılmış ve bunların \%59'u yeterli seviyede bulunmuştur (Şekil 8). Dönmez ve ark. (2015) Safranbolu ilçesi sitelerinin \%65'inde peyzaj donatı elemanlarının kullanıldığını belirlemişlerdir. Genel anlamda, sitelerin çoğunluğunda peyzaj donatı elemanlarının kullanıldığı bulunmuştur. Yeşil ve Yılmaz (2007) çocukların ve gençlerin toplu konut bahçelerinde çocuk oyun elemanları, basketbol ve voleybol sahaları vb. oyun elemanlarına ilgi gösterdiklerini ve bu tip donatı elemanlarından uygun olanlarının her toplu konut bahçesine yapılması gerektiğini vurgulamışlardır.

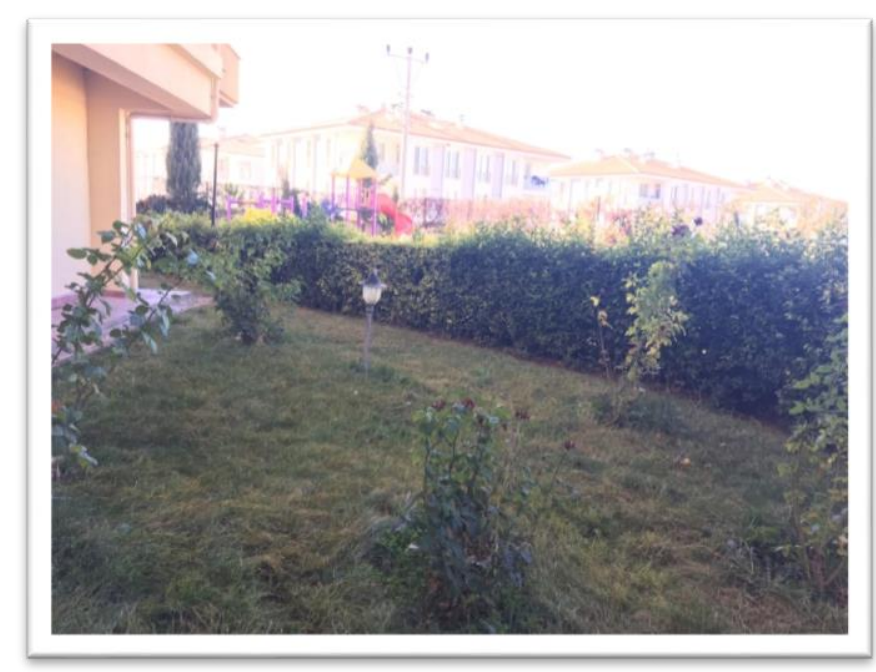

Şekil 8. Site Peyzaj Donatı Elemanı (Yakamoz Sitesi)

\section{SONUÇ VE ÖNERILER}

Çalışmanın bulguları bir bütün olarak değerlendirildiğinde, Yakamoz sitesinde ölçütlerin tamamı mevcut ve yeterli bulunmuştur. TOKI konutlarında güvenlik ölçütü dışında diğer ölçütler mevcut ve yeterli iken, TOKi1 konutlarında ise tüm ölçütler mevcut olmasına karşın, güvenlik ve otopark ölçütleri yetersiz olarak belirlenmiştir. Kullanıcıların toplu konut ve siteleri seçmelerinde, oturma-dinlenme alanları, çocuk oyun alanları, spor alanları, güvenlik, otopark ve bitkisel tasarım ölçütlerinin önemli hususlar olması sebebiyle yeni inşa edilecek sitelerde bu ölçütlerin ilgili kişi ve kurumlarca göz önüne alınması son derece önemlidir.

\section{KAYNAKLAR}

Aslan, F. (2007). Toplu Konut Yerleşimlerinde Peyzaj Tasarımı ve Yönetimi Sorunlarının Çözümünün, Ankara Koru-Yön Örneğinde İrdelenmesi, Ankara Üniversitesi Fen Bilimleri Enstitüsü, Yüksek Lisans Tezi, Ankara.

Atmış, E., Özden, S., Lise, W. (2007) Urbanization pressures on the natural forests in Turkey: an overview. Urban for Urban Gree 6 (2): 83-92.

Aydemir, Ş.,Erkonak Aydemir, S., Şen Beyazlı, D., Öktan, N., Öksüz, A.M., Sancar, C., Özyaba, M. (2004). Aydın Türk. Y. Kentsel Alanların Planlanması ve Tasarımı, Akademi Kitabevi, IBER Matbaacılık, 557 s., Trabzon.

Cetin, M. (2015a). Using GIS analysis to assess urban green space in terms of accessibility: case study in Kutahya. International Journal of Sustainable Development \& World Ecology 22 (5), 420-424

Cetin, M. (2015b). Evaluation of the sustainable tourism potential of a protected area for landscape planning: a case study 
of the ancient city of Pompeipolis in Kastamonu. International Journal of Sustainable Development \& World Ecology 22 (6), 490-495

Cetin, M. (2015c). Determining the bioclimatic comfort in Kastamonu City, Environmental monitoring and assessment 187 (10), 640

Cetin, M. (2016a). Determination of bioclimatic comfort areas in landscape planning: A case study of Cide Coastline. Turkish Journal of Agriculture-Food Science and Technology $4(9), 800-804$

Cetin, M. (2016b). Sustainability of urban coastal area management: A case study on Cide. Journal of Sustainable Forestry 35 (7), 527-541

Cetin, M., Adiguzel, F., Kaya, O., Sahap, A. (2016). Mapping of bioclimatic comfort for potential planning using GIS in Aydin. Environment, Development and Sustainability, 1-15, doi:10.1007/s10668-016-9885-5

Demir, E. (1998). Kentsel Farklılaşma ve Kimlik: Ankara'da Konut Çevreleri Üzerine Bir Araştırma. Ankara Üniversitesi Sosyal Bilimler Enstitüsü, Doktora Tezi, 195s, Ankara.

DMi (2009). DMi Genel Müdürlüğü 2009 yılı Faaliyet Raporu. https://www.mgm.gov.tr/FILES/kurumsal/yatirimfaaliyet/2009faaliyetraporu.pdf

Dönmez, Y., Özyavuz, M., Gökyer, E. (2015). Safranbolu Kentinin Konut ve Site Alanlarının Yeşil Alan Durumlarının Saptanması. İnönü Üniversitesi Sanat ve Tasarım Dergisi, 5(11): 1-12.

Erata, K. (1998). Toplu Konutlarda Kullanıcı İsteklerini Sistematize Eden Bir Tasarım Rehberi, Trakya Üniversitesi Fen Bilimleri Enstitüsü, Yüksek Lisans Tezi, 200 s, Edirne.

Erdoğan, Ö. (2009). Toplu Konut Uygulamalarının Dış Mekan Tasarım İlkeleri Açısından İrdelenmesi: Adana Seyhan ve Yüreğir İlçeleri Örneği. Çukurova Üniversitesi Fen Bilimleri Enstitüsü, Yüksek Lisans Tezi, 155 s., Adana.

Eti, F.N. (1994). Halkalı Toplu Konut alanının Kullanım Sonrası Değerlendirilmesi, İÜ Fen Bilimleri Enstitüsü Yüksek Lisans Tezi, İstanbul.

Fırat, F. (2001). Konya Merkez ve Çevresindeki Konut Alanlarının İrdelenmesi. Gazi Üniversitesi Fen Bilimleri Enstitüsü, Yüksek Lisans Tezi, 177 s, Ankara.

Giritlioğlu, C. (1991). Şehirsel Mekan Ögeleri ve Tasarımı I. ITÜ Kütüphanesi Sayı: 1459, ITÜ Mimarlık Fakültesi Baskı Atölyesi, İstanbul.
Gür, Ş.Ö. (2000). Doğu Karadeniz Örneğinde Konut Kültürü. Yapı Endüstri Merkezi Yayınları, İstanbul.

Kaya, L.G.; Yücedağ, C.; Duruşkan, Ö. (2015). Burdur Gölü Havzasının Çevresel Açıdan İrdelenmesi, Mehmet Akif Ersoy Üniversitesi Fen Bilimleri Enstitüsü Dergisi 6(1): 6-10.

Koçhan, A., Çolak, A., Uzun, T., Berkman, A.N., Yegin, M., Güneş, E. (2011). Sustainable and Healthy Artificial Environments for Hot-Humid and Warm-Humid Climates. World Renewable Energy Congress, 8-13 May 2011, s. 30263033, Sweden.

Kuchelmeister, G., Braatz, S. (1993). Urban Forestry Revisited. Unasylva 173 (44): 3-12.

Kurdoğlu, O., Düzgüneş, E. Kurdoğlu, B.Ç. (2011). Kent Ormanlarının Kavramsal Hukuksal ve Çevresel Boyutuyla Değerlendirilmesi. Artvin Çoruh Üniversitesi Orman Fakültesi Dergisi, 12(1): 63-76.

Özçatalbaş, O., Erdoğan, R. (2013). Akdeniz Bahçeleri ve Günümüz peyzaj Tasarım Çalışmalarına Yansımaları. Peyzaj Mimarlığı 5. Kongresi, 14-17 Kasım 2013, Adana.

Özyavuz, M., Dönmez, Y.(2016). Konut ve Site Alanlarında Peyzaj Tasarımlarının Yeterliliği Üzerine Bir Araştırma: Tekirdağ Kenti. Ormancılık Dergisi, 12(2): 108-122.

Sayan, G. (2000). Türkiye'de Toplu Konut Alanlarında Mevcut Dış Mekan Planlama Kararlarının İrdelenmesi ve Plan Kararlarının Standartlaştırılması, Ankara Üniversitesi Fen Bilimleri Enstitüsü, Doktora Tezi, Ankara.

TÜIKK (2016). Burdur İli Nüfus Verileri. Türkiye istatistik Kurumu, Ankara.

Yaşar, Y., Düzgüneş, E. (2013). Peyzaj Tasarımına Sürdürülebilirlik Kavramının Entegrasyonu: Bir Stüdyo Çalışması. İnönü Üniversitesi Sanat ve Tasarım Dergisi, 3(7): 31-43.

Yeşil, M., Yılmaz, S. (2007). Erzurum Kentinde Konut Bahçelerinin Peyzaj Tasarım İlkelerine Göre İncelenmesi Üzerine Bir Araştırma. Atatürk Üniversitesi Ziraat Fakültesi Dergisi, 38(1): 25-35.

Yiğitbaşıŏlu, H., Uğur, A. 2010. Burdur Gölü Havzasında Arazi Kullanım Özelliklerinden Kaynaklanan Çevre Sorunları. Ankara Üniversitesi Çevrebilimleri Dergisi 2(2), 129143.

Yücedağ, C., Bingöl, B., Kaya, L.G. (2016). Forest Genetic Resources in Burdur, Turkey. Mehmet Akif Ersoy Üniversitesi İktisadi ve İdari Bilimler Fakültesi Dergisi, 3(5): 6-12. 